\title{
Adjustment Costs and Investment Efficiency of Business Groups in Korea
}

\author{
Taegi Kim \\ Department of Economics, Chonnam National University, Gwangju, South Korea \\ Email: tgkim@jnu.ac.kr
}

Received 29 March 2016; accepted 8 June 2016; published 13 June 2016

Copyright (C) 2016 by author and Scientific Research Publishing Inc.

This work is licensed under the Creative Commons Attribution International License (CC BY). http://creativecommons.org/licenses/by/4.0/

c) (i) Open Access

\begin{abstract}
This paper investigates investment efficiency of business groups in Korea. Business groups can centralize knowledge and group resources, which reduces the cost of entering a new industry. In view of Tobin's $q$, the adjustment costs of investment of business group firms are lower than those of independent firms. The empirical results show that the adjustment costs of business group firms are lower than those of independent firms, and that the output-capital ratio of business group firms is greater than that of independent firms. The results suggest that business group firms contribute to lowering the adjustment cost and to increasing investment, which, in turn, contribute to the growth of the Korean economy.
\end{abstract}

\section{Keywords}

\section{Growth, Firm, Investment, Tobin's q, Business Group, Korea}

\section{Introduction}

One of the economic obstacles facing a developing country is its lack of capital for investment. In addition to the uncertainties associated with investment, adjustment costs affect investors in new industries [1]. Tobin's $q$, which relates the value of a firm's equity to its replacement costs, explains the investment of a firm. A higher Tobin's $q$ is associated with a higher rate of investment by the firm. This paper addresses investment decisions in the context of Tobin's $q$ and examines the adjustment costs of investment.

A Korean business group, which is called as chaebol, is a family-owned corporate entity comprising a group of firms across various industries ranging from textiles to chemicals, electronics, motor vehicles, ship building, and, most importantly, construction. ${ }^{1}$ Amsden [2] explains that continuity in ownership and control of a Korean

${ }^{1} \mathrm{~A}$ chaebol is usually associated with its ownership. A small group of family members own stock of firms, allowing them to control the management decisions of a group of firms. 
chaebol contributes to centralized knowledge and group resources, which facilitate the intragroup transfer of money and personnel. The centralization of knowledge and infrastructure in a business group reduces the cost of entering a new industry.

The knowledge and inputs of a business group are shared across business group affiliates. This results in economies of scope. Chandler [3] [4] examined the historical perspective of firm growth and emphasized the role of economies of scope in the formation of large modern corporations. Panzar and Willig [5] formally showed that economies of scope occurred when capital stock was a shared input, because it was a quasi-public input and reduced the cost of the production of multi-goods by a corporation.

The adjustment costs of investment are reduced in a new industry by sharing the knowledge embodied in the capital goods of extant industries. Such sharing of knowledge increases the impact of the investment in a new industry. This paper examines the extent to which business groups occupy a favorable position compared with other potential entrants in a new industry in terms of the adjustment costs of investment.

Section 2 proposes adjustment costs of investment, and demonstrates that a firm's rate of investment is an increasing function of Tobin's $q$. Section 3 presents the estimates of the adjustment costs for business groups and compares them with those of independent firms. Finally, section 4 concludes this paper.

\section{Model}

\subsection{Adjustment Costs of Investment}

Let us assume a continuum of industries $s \in(0,1)$ in the economy. A firm $i$ produces a final good $s$. Note that the capital good $k_{i s}$ comprises both the fixed capital good as well as the variable input, that is $k_{i s} \equiv k_{i s}^{F}+k_{i s}^{V}$. Assume that

$$
k_{i s}^{F}=b_{s} k_{i s} ; 0<b_{s}<1
$$

where $b_{s}$ denotes a share of the per capita fixed capital in total capital stocks.

It should be noted that the final good $s$ is not produced until firm $i$ completes the investment in the fixed capital good required for the good s. The adjustment costs need to be considered for the installation of the fixed capital good $s$. The spillover effects of the investments of the preceding industries reduce the adjustment costs of the investments for the next industry.

It is commonly accepted that the adjustment costs are an increasing convex function of the rate of investment [1] [6] [7]. In such a view, the adjustment costs are measured either by the output loss in production or by the loss of capital inputs. Instead, we express the adjustment cost functions in terms of effective units of capital good s. Our measure of the adjustment costs was taken from Uzawa's formulation [8].

Following Uzawa [8], we represent the adjustment costs of the investment in terms of the efficiency units of the capital good $s$ :

$$
\tilde{k}_{\text {is }}=\tilde{\phi}\left(z_{\text {is }}\right) k_{\text {is }} ; 0<\tilde{\phi}\left(z_{\text {is }}\right)<1
$$

where $Z_{i s}$ is firm $i$ ' s rate of investment in industry $s$ :

$$
0<z_{\text {is }} \equiv \frac{I_{\text {is }}}{K_{\text {is }}}<1
$$

In particular, we express the effective unit of capital good $s$ in the logarithmic form of $z_{\text {is }} \forall s \in(0,1)$ :

$$
\tilde{\phi}\left(Z_{\text {is }}\right) \equiv 1-b_{s} \phi\left(Z_{\text {is }}\right)=1-\left[-b_{s} \operatorname{In}\left(Z_{\text {is }}\right)\right] ; 0<Z_{\text {is }}<1
$$

Note that the adjustment cost is $-b_{s} \ln \left(z_{i s}\right) .^{2}$ This expression suggests that no adjustment costs occur, when the rate of investment is equal to 1 because $-b_{s} \ln (1)=0 .^{3}$

The assumption that the effective units of capital increase as the rate of the investment increases implies that

\footnotetext{
${ }^{2}$ Note that the sign of $-b_{s} \ln \left(z_{i s}\right)$ is positive, since the value of $\ln (z)$ is always negative as the value of the investment rate $z$ is between 0 and 1.

${ }^{3}$ This function trivially fulfills Hayashi's homogeneous degree-one condition for investment (I) and capital stock (K) in the adjustment cost function.
} 
the adjustment costs operate in the direction opposite to that of the conventional increasing cost assumption. Equation (4) tells that the higher the requirement of this fixed capital good (that is, higher b), the higher the adjustment costs of the investments and the lower the effective unit of investment. Conversely, the lower the required fixed capital good, the higher the effective units of a capital good (i.e., the lower its adjustment cost).

It should also be noted that the effective unit of capital good $s \tilde{\phi}\left(z_{i s}\right)$ should be positive, and thus, the adjustment cost of investment $-b_{s} \ln \left(z_{i s}\right)$ should be less than 1 . If we add the rate of depreciation $(\delta)$ to the adjustment cost of a unit of investment, a critical rate of investment, $\hat{z}$, should be calculated from $-b_{s} \ln \left(z_{i s}\right)+\delta<1$. From this equation, we can see that the critical rate of investment, $\hat{z}$, increases with the increase in $b_{s}$. Sunk costs arise for the investment range of $0<z<\tilde{z}$. A relevant range of investments is $\hat{z}<z<1$, and the effective units of investment increase for its relevant range of $\hat{z}<z<1$.

During structural change, different sectors of an economy experience inherent adjustment costs. Entrance into a new sector involves the fixed costs of investments, such as managerial and administrative operations, the marketing of products, the collection of information, and basic knowledge about the production of good s. A business group can centralize knowledge about resources across industries. It shares the knowledge embodied in the fixed capital good $s$ of its preceding industries.

Ventura [9] proposes a growth model appropriate for the growth of a small open economy in East Asia. In the context of prices in the world good $s$ market, the small open economy is in a favorable position to increase output-capital ratio along the global technological frontier at constant factor prices.

In this paper, the Korean business group plays the role of exploring the AK technological frontier. At the constant factor prices of a small open economy, it is more advantageous for the business group to expand the scope of its operations across capital-intensive industries than to follow the capital-deepening path with a pre-existing firm in a given industry.

\subsection{Investment of a Firm}

A firm's profit, $\pi_{i \tau}$, is:

$$
\pi_{i t}=p_{i t} y_{i t}-\left[w_{i t} L_{i t}-v_{i t}\left(1+r_{t}+\delta\right) I_{i t}\right]
$$

We assume that the prices of the final good sand investment good $s$ are given. The price of the final goods is $p_{i \tau}$, and the price of the investment is denoted by $v_{i \tau}$. For purposes of convenience, we assume that $p_{i \tau}$ is unity.

An investment is constrained by both the amount of the loan, with an interest rate of $r_{\tau}$, and by $\delta$, the rate of depreciation of an investment good. The cost of the investment per unit of the investment is expressed by $v_{i \tau}\left(1+r_{\tau}+\delta\right)$.

Capital accumulates according to the usual dynamic equation:

$$
\dot{k}_{i \tau}=\tilde{\phi}_{i}\left(z_{i \tau}\right) k_{i \tau}-\delta k_{i \tau}
$$

A constant, $\delta$, is the rate of depreciation on a unit of a capital good. The accumulation of capital continues as far as it succeeds in its venture into a new industry. However, the accumulation of capital is limited due to the adjustment costs for the forthcoming investments in a new industry.

In this context, the goal of a firm is to maximize profits according to profit Equation (5), subject to the capital accumulation Equation (6).

$$
\begin{aligned}
& \max \int_{t}^{\infty} \pi(t) \mathrm{e}^{(-r t)} \mathrm{dt} \\
& \text { s.t. } \\
& \dot{k}(t)=k(t)[\tilde{\phi}(z(t))-\delta] \\
& k(t)>\hat{k}
\end{aligned}
$$

The total profit flow and value of capital stock in the maximization problem is expressed in the form of the following Hamiltonian function in a present-value discounted form: 


$$
H(k(t), I(t), \lambda(t))=\pi(t) \mathrm{e}^{-r t}+\tilde{\lambda}(t) k(t)[\tilde{\phi}(z(t)-\delta)]
$$

where $H($.$) is a present discounted value and \tilde{\lambda}(t)$ is a firm's present discounted shadow value of the capital good at time period $t$; that is, $\tilde{\lambda}(t)=\lambda(t) \mathrm{e}^{-r t}$. A discount factor, $r$, is the market interest rate.

The necessary conditions for this model are:

$$
\begin{aligned}
& \dot{\lambda}=-A(\tilde{\phi}(z)-b)-\lambda[(\tilde{\phi}(z)-b)-(r+\delta)]<0 \\
& {[b A+\lambda]-v z[1+(r+\delta)]=0} \\
& \lim _{\tau \rightarrow \infty} \lambda k \mathrm{e}^{-r t} \rightarrow 0
\end{aligned}
$$

The value $\lambda$ in the neighborhood of its rest point, $\dot{\lambda}=0$, is:

$$
\lambda=\frac{-A(\tilde{\phi}(z)-b)}{(\tilde{\phi}(z)-b)-(r+\delta)}
$$

Next, we consider the first-order condition for the capital stock on the second row of the Equation (11). This yields a demand for the following rate of investment:

$$
z(t)=b \frac{A+\lambda}{v(1+r+\delta)}=b q(z)
$$

where $q($.$) is Tobin's q defined as:$

$$
q(z)=\frac{A+\lambda}{v(1+r+\delta)}
$$

If we substitute the $\lambda$ of Equation (10) for the $q$ of Equation (12), we can find that Tobin's $q$ is a monotonically decreasing function of the adjustment cost function $\phi(z)$. The demand for the rate of investment $\mathrm{Z}$ is higher, the higher is the coefficient $b$, that is, the higher is the share of the fixed capital good in the investment.

\section{Empirical Examination}

This section presents the results of an empirical test regarding the relationship between a firm's investment demand and the adjustment costs of its investments. Our incorporation of the definition of Tobin's q allows us to present the investment demand function in a form appropriate for the regressions using the following equation:

$$
\frac{I}{K}=\beta_{0}+\beta_{1} q+\epsilon
$$

where $I$ is investment, $K$ is capital stock, and q is Tobin's $q .{ }^{4}$

We empirically investigated whether business group firms have an advantage over independent firms with regard to investment decisions using data from 131 firms for 1980-2008. All sample firms were manufacturing businesses registered with the Korean Stock Market during the period. Of the 131 sample firms, 31 are included in business groups, and the remaining 100 firms are independent firms.

Data regarding output, labor input, investment, capital, and stock prices at the firm level were derived from the Korea Information Service Financial Analysis System (KIS-FAS) Database. Price indices, which were used to obtain constant values, were obtained from the Bank of Korea website homepage (www.bok.or.kr).

The sample was divided into two groups to compare the investment effects of business group firms with those of independent firms, and the time was also divided between the period before and that after the financial crisis, because the investment behavior of Korean firms changed after the 1997 financial crisis. After the financial crisis, Korean firms successfully improved the financial structure through debt restructuring, and the performance of Korean firms improved. In particular, the profits of business group firms showed greater improvement than did those of independent firms [11]. Nevertheless, the investment rate of Korean firms decreased sharply after

\footnotetext{
${ }^{4}$ See Kim and Oh [10] for the detailed method of calculating Tobin's $q$.
} 
the crisis [11] [12].

Table 1 shows the average values of the selected variables for business group and independent firms. The average investment amount of business group firms was much greater than that of independent firms for all periods; before the crisis, the average investment amounts of business group and independent firms were 154.3 billion Korean Wons and 16.0 billion Korean Wons, respectively; they were 368.2 and 14.7 Korean Wons, respectively, after the crisis. During the after-crisis period, the investment gap between business group and independent firms increased compared with before the crisis.

In terms of the average value of capital stock, the size of business group firms was much greater than that of independent firms. During the entire period under evaluation, the prices of the average capital stock of business group and independent firms were 2176.7 and 225.5 billion Korean Wons, respectively. The average capital stock of business group firms cost about 10 times as much as that of independent firms.

Table 1 also shows that the rate of investment of business group firms (z) was greater than that of independent firms. Before the crisis, the average investment rates for business group and independent firms were 0.1933 and 0.1161, respectively; after the crisis, they were 0.0877 and 0.0631 , respectively; and they were 0.1449 and 0.0918, respectively, for the entire period. Business group firms invest more than independent firms even after normalizing investment amount to firm size. The rate of investment $(\mathrm{z})$ in both business group and independent firms decreased after the crisis.

Our model assumes that the production function of a business group firm conforms to AK technology, whereas that of an in dependent firm is characterized by diminishing returns. In this case, the output-capital ratio (A) of business group firms is greater than that of independent firms. Table 1 shows that the output/capital ratio A was greater in business group firms compared with independent firms both before and after the crisis. This indicates that AK technology applies more to business group firms than to independent firms.

The relationship between a firm's investment and Tobin's $q$ was examined with the regression model described in Equation (13). In this case, a panel data regression model with a year fixed effect was used. The regression results are presented in Table 1, which shows the data for business group firms and independent firms before and after the crisis. All coefficients of the variable q were positive and statistically significant at the $1 \%$ confidence level. This implies that firms invest more when their Tobin's $q$ increases.

It should be noted that the coefficient, $\beta_{1}$, is an estimator of the coefficient $b$ in equation (11), where $b$ is the fixed investment share in Equation (1). We calculated a business group firm's investment advantage over that of an independent firm. Note that the effective rate of capital is defined as $\tilde{\phi}(z)=1+b \cdot \ln (z) \tilde{\phi}(z)=1+b \cdot \ln (z)$, where $b$ is the share of fixed capital investment and $\ln (z)$ is the adjustment cost of the investment.

As we can see in Table 2, the estimated $\mathrm{b}$ of the business group $\left(b_{c}\right)$ were greater than are those of the independent firms $\left(b_{n c}\right)$ during all periods. We calculated the fixed capital advantage of business group firms using the following equation:

$$
\text { Fixed capital advantage }(\text { FCA })=\frac{b_{c}-b_{n c}}{b_{n c}}
$$

The results presented in Table 3 show that the fixed capital advantage of business group firms was $22.3 \%$ before the crisis, $86.9 \%$ in after the crisis, and $55.6 \%$ for the whole period. Table 3 also shows that the fixed

Table 1. Average value of the selected variables for business group and independent firms.

\begin{tabular}{|c|c|c|c|c|c|c|c|c|}
\hline & \multicolumn{2}{|c|}{ Investment } & \multicolumn{2}{|c|}{ Capital Stock } & \multicolumn{2}{|c|}{$\mathrm{z}(=\mathrm{I} / \mathrm{K})$} & \multicolumn{2}{|c|}{ A } \\
\hline & $\begin{array}{l}\text { Business } \\
\text { group }\end{array}$ & Independent & $\begin{array}{l}\text { Business } \\
\text { group }\end{array}$ & Independent & $\begin{array}{l}\text { Business } \\
\text { group }\end{array}$ & Independent & $\begin{array}{l}\text { Business } \\
\text { group }\end{array}$ & Independent \\
\hline Before Crisis & 154.3 & 16.0 & 1108.9 & 180.1 & 0.19333 & 0.11618 & 1.16244 & 1.15888 \\
\hline After Crisis & 368.2 & 14.7 & 3438.7 & 279.0 & 0.08771 & 0.06311 & 1.07460 & 1.01829 \\
\hline Whole Period & 252.5 & 15.4 & 2176.7 & 225.5 & 0.14492 & 0.091856 & 1.12218 & 1.09444 \\
\hline
\end{tabular}

Note: 1) The variables of Investment and Capital stocks are the 2005 constant values. Units are one billion Korean Won. 2) z: rate of investment $=\mathrm{I} / \mathrm{K}$, A: output/capital ratio. The values of $\mathrm{z}$ and A are the simple averages of each firm's $\mathrm{z}$ and $\mathrm{A}$ for each group.

${ }^{5}$ Another regression analysis was performed that included the lagged I/K variable as an explanatory variable to determine the long-run effect The regression results show that all the coefficients of $\beta_{1}$ were significant and that the adjusted ACA was $28.3 \%$ and $25.6 \%$ before and after the crisis, respectively. The results are similar to the values of adjusted ACA in Table 3. 
Table 2. Regression results for business group and independent firms.

\begin{tabular}{|c|c|c|c|c|}
\hline & Firm & Intercept & $\beta_{1}(=b)$ & $R^{2}$ \\
\hline \multirow{2}{*}{ Before Crisis } & Business group & $\begin{array}{c}0.08791^{* *} \\
(1.99)\end{array}$ & $\begin{array}{c}0.108166^{* * * *} \\
(2.83)\end{array}$ & 0.0663 \\
\hline & Independent & $\begin{array}{c}-0.00203 \\
(0.09)\end{array}$ & $\begin{array}{c}0.088447^{* * *} \\
\quad(4.58)\end{array}$ & 0.0372 \\
\hline \multirow{2}{*}{ After Crisis } & Business group & $\begin{array}{c}0.00730 \\
(0.39)\end{array}$ & $\begin{array}{c}0.074009 * * * \\
\quad(6.44)\end{array}$ & 0.1227 \\
\hline & Independent & $\begin{array}{c}0.04701^{* * * *} \\
\quad(4.18)\end{array}$ & $\begin{array}{c}0.039600^{* * * *} \\
\quad(4.98)\end{array}$ & 0.0340 \\
\hline \multirow{2}{*}{ Whole Period } & Business group & $\begin{array}{c}-0.00036 \\
(0.01)\end{array}$ & $\begin{array}{c}0.081475^{* * *} \\
\quad(5.50)\end{array}$ & 0.2237 \\
\hline & Independent & $\begin{array}{c}0.03652^{* * *} \\
(2.70)\end{array}$ & $\begin{array}{c}0.052345^{* * *} \\
(6.08)\end{array}$ & 0.0817 \\
\hline
\end{tabular}

Note: 1) The values in ( ) are $t$-values. ** and *** indicate that the coefficients are statistically significant at the $5 \%$ and $1 \%$ level, respectively. 2) $\beta_{1}$ is equal to the value of $b$ in Equation (13).

Table 3. Business group firms’ adjustment costs advantage.

\begin{tabular}{cccc}
\hline \multirow{2}{*}{ Period } & $\begin{array}{c}\text { Fixed Capital Advantage } \\
\text { (FCA) }\end{array}$ & $\begin{array}{c}\text { Adjustment Cost Advantage } \\
\text { (ACA) }\end{array}$ & Adjusted ACA \\
\hline Before Crisis & 22.3 & -23.7 & -28.9 \\
After Crisis & 86.9 & -11.9 & -22.3 \\
Whole Period & 55.6 & -19.1 & -29.7 \\
\hline
\end{tabular}

Note: 1) Negative ACA values mean that the adjustment costs of business group firms were lower than those of independent firms. 2) Adjusted ACA was calculated from $\mathrm{ACA}^{*}(1+\mathrm{FCA} / 100)$

capital investment share of business group firms was greater than that of independent firms, ${ }^{5}$ and that this advantage increased after the financial crisis. This was expected given that the fixed capital stock of business group firms increased at a faster rate compared with independent firms.

Next, we calculated the adjustment costs of the investment of each group. We calculated adjustment cost, $-\ln (z)$, using the values of $\mathrm{z}$ in Table 1 . We used the following equation to determine the advantage of the business group firms' adjustment costs:

$$
\text { Adjustment cost advantage }(\text { ACA })=\frac{\left[-\ln \left(z_{c}\right)\right]-\left[-\ln \left(z_{n c}\right)\right]}{\left[-\ln \left(z_{n c}\right)\right]}
$$

According to the adjustment cost advantage (ACA) values in Table 3, the adjustment costs of business group firms were $19.1 \%$ lower than those of independent firms during the whole period. In addition, the adjustment cost advantage of business group firms was greater before the crisis compared with after the crisis, with values of $23.7 \%$ and $11.9 \%$, respectively. In Korea, it was harder for a firm to receive an investment loan from banks before the crisis compared with after the crisis. In this case, the adjustment cost advantage of business group firms would be greater before the crisis than after the crisis because business group firms can share knowledge and resources with one another.

The adjustment cost of an investment is related to the fixed capital stock. The adjusted ACA, which considers the fixed capital advantage of business group firms, can be calculated with the following equation: ACA $(1+$ FCA). The values of the adjusted ACA in Table 3 show that the adjustment costs of investments by business group firms were lower than those of independent firms. The adjusted adjustment cost advantage was also greater before crisis than the after crisis, with values of $28.9 \%$ and $22.3 \%$, respectively. This means that if we consider the fixed capital advantage of business group firms, the adjustment cost advantage of business group firms increases.

As assumed in the model, the empirical results show that the adjustment cost of business group firms is lower than that of independent firms. This result suggests that the Ak technology of a business group contributes to 
lowering its adjustment costs relative to those of independent firms.

\section{Concluding Remarks}

This paper investigates investment efficiency of business groups in Korea. Business groups can centralize knowledge and group resources, which reduces the cost of entering a new industry. The growth of Korean business groups is sustained by their high investment rates. Since the adjustment cost of investment is low for a firm of business group, a business group can enter a new industry more easily than an independent firm. In this respect, a Korean business group acts as a conduit for structural change in the Korean economy.

As assumed in the model, the empirical results show that the output-capital ratio of business group firms is higher than that of independent firms, and that the adjustment cost of business group firms is lower than that of independent firms. This result suggests that the lower adjustment cost of business group contributes to increasing investment in Korean economy.

Finally, the higher output-capital ratio of business group is based on the presumption that the spillover effects of foreign technology are not exhausted. However, as the developmental stage of Korean business group reaches the level at which its technological distance from that of the world frontier is narrowed, the growth of Korean business group must rely on their own innovative strategies.

\section{Funding}

This work was supported by the National Research Foundation of Korea Grant funded by the Korean Government (NRF-2014S1A2A2027622). The theoretical model of this paper was given by Shin-Haing Kim.

\section{References}

[1] Lucas Jr., R.E. (1967) Adjustment Costs and the Theory of Supply. Journal of Political Economy, 75, 321-334. http://dx.doi.org/10.1086/259289

[2] Amsden, A.H. (1989) Asia’s Next Giant: South Korea and Late Industrialization. Oxford University Press, New York and Oxford.

[3] Chandler, A.D. (1990) Scale and Scope. Harvard University Press, Cambridge.

[4] Chandler, A.D. (1992) What Is a Firm?: A Historical Perspective. European Economic Review, 36, 483-492. http://dx.doi.org/10.1016/0014-2921(92)90106-7

[5] Panzar, J.C. and Willig, R.D. (1981) Economies of Scope. American Economic Review, 71, 268-272.

[6] Hayashi, F. (1982) Tobin’s Marginal q and Average q: A Neoclassical Interpretation. Econometrica, 50, $213-224$. http://dx.doi.org/10.2307/1912538

[7] Blundell, R., Bond, S., Devereux, M. and Schiantaralli, F. (1992) Investment and Tobin’s Q: Evidence from Company Panel Data. Journal of Econometrics, 51, 233-257. http://dx.doi.org/10.1016/0304-4076(92)90037-R

[8] Uzawa, H. (1969) Time Preference and the Penrose Effect in a Two-Sector Model of Economic Growth. Journal of Political Economy, 77, 628-652. http://dx.doi.org/10.1086/259554

[9] Ventura, J. (1997) Growth and Interdependence. Quarterly Journal of Economics, 112, 57-84. http://dx.doi.org/10.1162/003355397555127

[10] Kim, T. and Oh, K.Y. (2013) The Effects of Firm's Land Value on the Investment in Korea. Journal of Korean Economic Studies, 31, 133-160.

[11] Lee, B. (2008) Analysis of the Effect of Corporate Restructuring on the Economic Performance Before and After the Financial Crisis. Research Reports, Korea Economic Research Institute, Seoul.

[12] Hong, K.-S. (2008) The Post-Crisis Structural Changes of Korea’s Corporate Sector. In: Park, Y.C., Ed., Korea’s Foreign Exchange Crisis 10 Years, Korea Economic Research Institute, Seoul. 